\title{
Steric effects of alkyl substituents in silicon chemistry
}

\author{
Anu Ploom, Dmitri Panov, and Ants Tuulmets* \\ Institute of Organic and Bioorganic Chemistry, University of Tartu, \\ Jakobi 2, 54014 Tartu, Estonia \\ E-mail: ants.tuulmets@ut.ee
}

\section{Dedicated to Professor Edmunds Lukevics on his $70^{\text {th }}$ birthday}

\begin{abstract}
Reactivity data for a number of reactions taking place at $\mathrm{Si}$ atoms in organosilicon compounds containing a variety of alkyl groups have been examined for statistical correlations with steric parameters. Four practically equivalent sets of parameters are now available for quantitative description of steric effects of alkyl substituents in organosilicon compounds. Alkyl substituents contribute to the reactivity exclusively with their steric effects. Steric effects in silicon compounds are additive.
\end{abstract}

Keywords: Correlation analysis, silicon compounds, steric effects, substituent constants

\section{Introduction}

To correlate structural effects with chemical and physical properties it is necessary to differentiate between steric and electronic effects in relation to a property. In traditional organic chemistry this issue has a long history and protocols for quantitative separation of the effects are available, ${ }^{1-4}$ however, in organometallic chemistry a general and unequivocal approach still needs to be developed. 5,6

The importance of steric effects in organosilicon chemistry has always been stressed ${ }^{7-10}$ and several attempts of quantitative description of the effects have been done. ${ }^{8,10-14}$

Effects of aliphatic substituents on the reactivity of organosilicon compounds have been described since long with the Taft equation (Eq.1), ${ }^{8,10}$ where the two last terms express the independent contributions from polar (inductive) and steric effects respectively. ${ }^{1,3}$

$$
\log k=\log k_{0}+\rho^{*} \sigma^{*}+\delta E_{s}
$$

The $\sigma^{*}$-values measure the polar effects of substituents. However, there have been numerous contributions $s^{2,3,15,16}$ casting doubt on the status of $\sigma^{*}$-values for alkyl groups. As the 
main conclusion, it has been stressed that alkyl substituents do not exert any inductive effect and the $\sigma^{*}$-values of alkyl groups are an artifact.

Also the Taft $E_{\mathrm{s}}$ scale of steric parameters has been subjected to criticism from different viewpoints. Several authors ${ }^{17,18}$ have maintained that the Taft $\mathrm{E}_{\mathrm{s}}$ parameters do not represent a complete separation of steric and polar effects and have attempted to improve the scale in various ways. Dubois et al. ${ }^{19}$ have criticized the basic assumptions used in obtaining the Taft $\mathrm{E}_{\mathrm{s}}$ scale and have proposed a revised and extended scale based on a single defining reaction.

Silicon chemists have mainly used correlations for which the substituent constants have been defined in organic reactions. ${ }^{5,8,10}$ However, the steric parameters derived from reactions of organic carbonyl compounds have been moderately suitable for description steric effects in reactions taking place at $\mathrm{Si}$ atoms. Considering the greater length of $\mathrm{C}-\mathrm{Si}$ as compared to $\mathrm{C}-\mathrm{C}$ bonds some incompatibility of Taft type scales with reactions at Si center could be expected.

Cartledge ${ }^{11}$ defined a set of $\mathrm{E}_{\mathrm{s}}(\mathrm{Si})$ parameters for eight alkyl groups and for $\mathrm{H}$ from rates of acid-catalyzed hydrolysis of $\mathrm{SiH}$ compounds. For eight reaction series the correlation with $\mathrm{E}_{\mathrm{s}}(\mathrm{Si})$ was better or comparable with these where Taft type constants were involved. The Cartledge scale of $\mathrm{E}_{\mathrm{s}}(\mathrm{Si})$ constants appeared to be in a good correlation with $v$ ' parameters derived by Charton $^{20}$ for correlation of the nucleophilic substitution at four-coordinate carbon.

Shimizu et al. ${ }^{12}$ have proposed a quantitative scale for the structural effect on reactivity toward nucleophilic displacement at silicon using the rates of solvolysis for triorganochlorosilanes. The steric constants $\mathrm{E}_{\mathrm{s}}{ }^{\mathrm{Si}}$ by Shimizu et al. for alkyl groups correlate with Cartledge $\mathrm{E}_{\mathrm{s}}(\mathrm{Si})$ constants as well as with v' parameters by Charton. Rühlmann et al. ${ }^{13,14}$ apply a modified Taft scale fitted for silane reactions.

The major difference in the parameters derived from silicon compounds and those derived from carbonyl compounds (the scales by Taft or Dubois) is a greater effect of branching in $\alpha$ position to the silicon center than that of branching in $\beta$-position. Cartledge found the steric effects in silicon reactions to be additive. ${ }^{11}$ Interestingly, this is not the case for organic reactions. $^{3,18}$ Charton has concluded ${ }^{20}$ that steric effects are more sensitive to reaction type than to the identity of the atom under attack and that a reaction involving expansion of coordination from four to five will show a different sensitivity to $\alpha$ and $\beta$ branching than a reaction involving change of coordination from three to four, e.g. at carbonyl carbon.

In a great number of works reactivity data for silicon compounds have been correlated with Taft $\sigma^{*}$-constants (see review, ${ }^{10}$ and refrs. ${ }^{21-23}$ ). However, the authors never paid attention to a close correlation between $\sigma^{*}$ and steric $\mathrm{E}_{\mathrm{s}}$ constants $(\mathrm{R}=0.865$, or without Me-group $\mathrm{R}=0.950)$. Thus, the correlations actually described the steric effects of alkyl substituents. In less numerous cases, where alkyl and polar groups were involved and two-parameter correlations including both $\sigma^{*}$ and $\mathrm{E}_{\mathrm{s}}$ constants were applied, the results are confused in an extent depending on the relative contribution of alkyl compounds in a reaction series. Anyhow, the physical sense of such correlations remains obscure. Therefore, as already stressed by Cartledge, ${ }^{11}$ substantial amounts of reactivity data in organosilicon chemistry need to be reexamined and reinterpreted. So far, this 
is only Rühlmann group which has taken steps toward this goal, ${ }^{13}$ however, details of the work have not been published.

We have undertaken a revision of quantitative literature data for the reactivity of organosilicon compounds in order to ascertain the state-of-art in the domain and to outline subsequently a general protocol for correlation analysis in organosilicon chemistry. In this work we confine ourselves to steric effects of alkyl substituents. A reliable quantitative description of the reactivity of alkyl compounds is necessary for further separation of polar and steric effects in silicon chemistry.

\section{Results and Discussion}

As mentioned above, several quantitative scales have been proposed for description of steric effects by alkyl substituents on organosilicon compounds. Chronologically, the first among them is the $\mathrm{E}_{\mathrm{s}}(\mathrm{Si})$ scale by Cartledge. ${ }^{11}$ Although Cartledge was "reluctant to promote extensive use of a new set of parameters," the scale appeared to be as good as other sets under consideration (vide infra) and subsequently we compare other scales with that proposed by Cartledge.

Only reaction series with a sufficient span of reaction rates and involving at least five different substituents were considered in our analysis. As is seen in Table 1 the reactions are predominantly nucleophilic displacements at silicon atom. Alkyl substituents in attacking nucleophiles have been varied in few works. ${ }^{23-26}$ Two of them are involved in Table 1. Also the reaction series used in Cartledge work ${ }^{11}$ X-XVII are included to provide a comparison between the steric susceptibilities of the reactions. Series I-IX were primarily not correlated with the $\mathrm{E}_{\mathrm{s}}(\mathrm{Si})$ scale.

Four sets of steric constants for alkyl substituents were considered, namely $\mathrm{E}_{\mathrm{s}}(\mathrm{Si})$ scale by Cartledge, ${ }^{11} v$ ' parameters by Charton, ${ }^{20} \mathrm{E}_{\mathrm{s}}{ }^{\mathrm{Si}}$ constants by Shimizu et al., ${ }^{12}$ and the set of steric constants $\mathrm{E}_{\mathrm{s}}(\mathrm{R})$, by Rühlmann et al. ${ }^{13}$

Excellent correlations of series VIII with $\mathrm{E}_{\mathrm{s}}(\mathrm{Si})$ and v' parameters ${ }^{26}$ enabled to calculate missing values of steric constants for $s$-Bu group (Table 2). It appeared that the original $\mathrm{E}_{\mathrm{s}}(\mathrm{Si})$ value for $c$-Hex group was inaccurate. From series I and III-V a corrected value $-0.687 \pm 0.031$ was obtained. Similarly, a correction for $v{ }^{`}$ of Me-group equal to $-0.124 \pm 0.017$ was found from series I and IV-VII. Further the scale of $v$ ' parameters was shifted to adjust the origin to methyl. The improved sets of steric parameters are collected in Table 2. All the scales are in good correlations with each other, e.g. $\mathrm{E}_{\mathrm{s}}(\mathrm{Si})$ for alkyl groups has correlation coefficients with $\mathrm{E}_{\mathrm{s}}{ }^{\mathrm{Si}}$, $\mathrm{E}_{\mathrm{s}}(\mathrm{R})$, and $v$ ' equal to $0.991,0.996$, and 0.996 respectively. When remote points for $\mathrm{H}$ are involved, the correlations are slightly inferior, however, the correlation coefficients still exceed 0.90 . For this reason only results of correlations with $\mathrm{E}_{\mathrm{s}}(\mathrm{Si})$ scale are shown in Table 1 .

Prevalence of good and excellent correlations in Table 1 is an evidence of exclusively steric effects of alkyl substituents. Likewise, additivity of the steric effects is obvious since parameters $\mathrm{E}_{\mathrm{s}}(\mathrm{Si})$ defined $^{11}$ from experimental data for compounds with several different or 
multiple alkyl groups in each (series X and XI) appeared to be successfully applicable to any organosilicon reaction in Table 1 thus corroborating the supposition by Cartledge. ${ }^{11}$

The results in Table 1 show a great diversity of susceptibilities to steric effects. Applicability of this kind of correlation analysis to such a wide range of mechanistically distinct reactions is impressive. In the absence of reliable quantitative data for polar effects on the reactions an extensive analysis of structure-reactivity relationships involving polar substituents seems to be premature. However, enhanced susceptibility of reactions with sterically encumbered compounds is obvious. Also, interrelations between reaction mechanisms and steric effects are evident (cf., e.g. series III and IV, X and XI, or XIV and XV), thus giving promise of fruitful application of correlation analysis in organosilicon chemistry.

Table 1. Correlations of rate data with Cartledge steric parameters $\mathrm{E}_{\mathrm{s}}(\mathrm{Si})$

\begin{tabular}{|c|c|c|c|c|}
\hline Reaction, solvent & $\mathrm{n}^{\mathrm{a}}$ & $\delta^{\mathrm{b}}$ & $\mathrm{R}^{\mathrm{c}}$ & $S^{d}$ \\
\hline I. $\mathrm{RMe}_{2} \mathrm{SiCl}+\mathrm{Me}_{3} \mathrm{SiOLi}, \mathrm{Et}_{2} \mathrm{O}^{\mathrm{e}}$ & $7^{f}$ & $1.50 \pm 0.30$ & 0.911 & 0.184 \\
\hline II. $\mathrm{RMe}_{2} \mathrm{SiCl}+\mathrm{PhMe}_{2} \mathrm{SiOLi}, \mathrm{Et}_{2} \mathrm{O}^{\mathrm{e}}$ & $6^{\mathrm{f}, \mathrm{g}}$ & $1.23 \pm 0.16$ & 0.969 & 0.077 \\
\hline III. $\mathrm{RMe}_{2} \mathrm{SiCl}+\mathrm{Me}_{2} \mathrm{CHOLi}, \mathrm{Et}_{2} \mathrm{O}^{\mathrm{e}}$ & $7^{\mathrm{f}}$ & $1.55 \pm 0.11$ & 0.989 & 0.064 \\
\hline IV. $\mathrm{RMe}_{2} \mathrm{SiCl}+\mathrm{H}_{2} \mathrm{O}, \mathrm{H}_{2} \mathrm{O} /$ diox $^{\mathrm{h}}$ & $8^{\mathrm{f}}$ & $2.28 \pm 0.12$ & 0.991 & 0.152 \\
\hline V. $\mathrm{RSiCl}_{3}+\mathrm{Me}_{3} \mathrm{SiOLi}, \mathrm{Et}_{2} \mathrm{O}^{\mathrm{i}}$ & $7^{\mathrm{f}}$ & $1.54 \pm 0.10$ & 0.990 & 0.059 \\
\hline VI. $\mathrm{RSiCl}_{3}$ acetolysis, $\mathrm{Ac}_{2} \mathrm{O}^{\mathrm{j}}$ & 6 & $1.59 \pm 0.19$ & 0.973 & 0.082 \\
\hline VII. $\mathrm{ROH}+\mathrm{PhMe}_{2} \mathrm{SiOH}, \mathrm{HCl} / \mathrm{diox}^{\mathrm{k}}$ & 6 & $0.70 \pm 0.07$ & 0.981 & 0.030 \\
\hline VIII. $\mathrm{RMgCl}+\mathrm{MeViSiCl}_{2}, \mathrm{Et}_{2} \mathrm{O}$ & $5^{1}$ & $1.04 \pm 0.03$ & 0.998 & 0.032 \\
\hline IX. $\mathrm{RMe}_{2} \mathrm{SiH}+\mathrm{KOH}, \mathrm{EtOH} / \mathrm{H}_{2} \mathrm{O}^{\mathrm{m}}$ & 6 & $1.28 \pm 0.06$ & 0.996 & 0.028 \\
\hline $\mathrm{X} . \mathrm{R}_{3} \mathrm{SiH}+\mathrm{HCl}, \mathrm{EtOH} / \mathrm{H}_{2} \mathrm{O}^{\mathrm{n}}$ & $9^{p}$ & $1.05 \pm 0.02$ & 0.998 & 0.058 \\
\hline $\mathrm{XI} . \mathrm{R}_{3} \mathrm{SiH}+\mathrm{KOH}, \mathrm{EtOH} / \mathrm{H}_{2} \mathrm{O}^{\mathrm{n}}$ & 10 & $1.82 \pm 0.05$ & 0.996 & 0.086 \\
\hline XII. $\mathrm{R}_{3} \mathrm{SiH}+\mathrm{Br}_{2}, \mathrm{DMF}^{\mathrm{n}}$ & 8 & $0.44 \pm 0.13$ & 0.817 & 0.179 \\
\hline XIII. $\mathrm{R}_{3} \mathrm{SiH}+\mathrm{O}_{3}, \mathrm{CCl}_{4}{ }^{\mathrm{n}}$ & 10 & $-0.31 \pm 0.04$ & 0.928 & 0.133 \\
\hline XIV. $\mathrm{R}_{3} \mathrm{SiOPh}+\mathrm{H}^{+}, \mathrm{EtOH} / \mathrm{H}_{2} \mathrm{O}^{\mathrm{n}}$ & 5 & $2.85 \pm 0.17$ & 0.995 & 0.177 \\
\hline $\mathrm{XV} . \mathrm{R}_{3} \mathrm{SiOPh}+\mathrm{OH}^{-}, \mathrm{EtOH} / \mathrm{H}_{2} \mathrm{O}^{\mathrm{n}}$ & 5 & $4.25 \pm 0.15$ & 0.998 & 0.156 \\
\hline XVI. $\mathrm{R}_{3} \mathrm{SiF}+\mathrm{H}_{2} \mathrm{O}, \mathrm{H}_{2} \mathrm{O} / \mathrm{AcMe}^{\mathrm{n}}$ & 5 & $1.91 \pm 0.19$ & 0.985 & 0.206 \\
\hline XVII. $\mathrm{R}_{3} \mathrm{SiH}+1$-hexyne, $\mathrm{THF}^{\mathrm{n}}$ & 6 & $0.70 \pm 0.16$ & 0.907 & 0.123 \\
\hline
\end{tabular}

${ }^{a}$ Number of compounds in the correlation. ${ }^{b}$ Regression coefficient. ${ }^{c}$ Correlation coefficient.

${ }^{\mathrm{d}}$ Standard deviation of regression. ${ }^{\mathrm{e}} \mathrm{Ref} .{ }^{13}{ }^{\mathrm{f}}$ Point for $c$-Hex used to correct the $\mathrm{E}_{\mathrm{s}}(\mathrm{Si})$ value. ${ }^{\mathrm{g}}$ Point for Me removed. ${ }^{\mathrm{h}}$ Ref. ${ }^{12}{ }^{\mathrm{i}}$ Ref. ${ }^{14}{ }^{\mathrm{j}} \mathrm{Ref} .{ }^{27}{ }^{\mathrm{k}} \mathrm{Ref} .{ }^{23}{ }^{1}$ Point for $s$-Bu used to calculate the $\mathrm{E}_{\mathrm{S}}(\mathrm{Si})$ value. ${ }^{\mathrm{m}}$ Ref. ${ }^{28 \mathrm{n}} \mathrm{Ref}^{11}{ }^{\mathrm{p}}$ Reference series of Cartledge, corrected value of $\mathrm{E}_{\mathrm{s}}(\mathrm{Si})$ for $c$-Hex used. 
Table 2. Revised sets of steric substituent constants

\begin{tabular}{lcccc}
\hline $\mathrm{R}$ & $-\mathrm{E}_{\mathrm{s}}(\mathrm{Si})^{\mathrm{a}}$ & $-\mathrm{E}_{\mathrm{S}}^{\mathrm{Sib}}$ & $-\mathrm{E}_{\mathrm{S}}(\mathrm{R})^{\mathrm{c}}$ & $v^{{ }^{\mathrm{d}}}$ \\
\hline $\mathrm{H}$ & -1.12 & -0.948 & -1.00 & -0.23 \\
$\mathrm{Me}$ & 0 & 0 & 0 & $0^{\mathrm{e}}$ \\
$\mathrm{Et}$ & 0.149 & 0.261 & 0.28 & 0.15 \\
$\mathrm{Pr}$ & 0.216 & 0.315 & 0.36 & 0.19 \\
$\mathrm{Bu}$ & 0.225 & 0.348 & 0.39 & 0.19 \\
$i-\mathrm{Bu}$ & 0.405 & 0.400 & 0.55 & 0.32 \\
$i-\mathrm{Pr}$ & 0.556 & 0.677 & 0.70 & 0.39 \\
$c-\mathrm{Hex}$ & $0.69^{\mathrm{e}}$ & 0.757 & 0.79 & - \\
$s-\mathrm{Bu}$ & $0.67^{\mathrm{f}}$ & 0.704 & 0.87 & $0.49^{\mathrm{f}}$ \\
$t-\mathrm{Bu}$ & 1.46 & 1.670 & - & 1.00 \\
\hline
\end{tabular}

${ }^{\mathrm{a}}$ Constants by Cartledge. ${ }^{11}$ b Constants by Shimizu et al. ${ }^{12}$ Constants by Rühlmann et al. ${ }^{13}$

${ }^{\mathrm{d}}$ Charton parameters ${ }^{20}$ adjusted to $v^{{ }_{\mathrm{Me}}}=0 .{ }^{\mathrm{e}}$ Value corrected in this work (see text). ${ }^{\mathrm{f}}$ Calculated in ref. $^{26}$

\section{Conclusions}

Available quantitative literature data concerning the reactivity of organosilicon compounds were collected and the data for compounds with alkyl substituents were subjected to a correlation analysis. Four sets of steric constants for alkyl substituents of silicon compounds were considered. Some missing values were calculated and several corrections were made. It appears that the improved sets of parameters are practically equivalent and almost equally applicable for quantitative description of steric effects exerted by alkyl substituents upon the reactivity of organosilicon compounds. Statistical treatment of 17 representative reaction series lead to results corroborating former suppositions that (i) alkyl substituents contribute to the reactivity exclusively with their steric effects, and (ii) steric effects in silicon compounds are additive.

\section{Acknowledgments}

This work was financially supported by Dow Corning Corporation (Midland, USA), and Estonian Science Foundation (Grant No 6512). 


\section{References}

1. Taft, R. W. Jr. In Steric Effects in Organic Chemistry, Newman, M. Ed., Wiley: New York, 1956, Chapt. 13.

2. Chapman, N. B.; Shorter, J. Eds. Advances in Linear Free Energy Relationships, Plenum Press: London, 1972.

3. Shorter, J. Correlation Analysis in Organic Chemistry, Clarendon Press: Oxford, 1973.

4. Williams, A. Free Energy Relationships in Organic and Bio-organic Chemistry, RSC: Cambridge, 2003.

5. Galkin, V. I.; Sayakhov, R. D.; Tcherkasov, R. A. Usp. Khim. 1991, 60, 1617.

6. White, D.; Coville, N. J. Adv. Organomet. Chem. 1994, 36, 95.

7. Eaborn, C. Organosilicon Compounds, Butterworths: London, 1960.

8. Sommer, L. H. Stereochemistry, Mechanism and Silicon, McGraw-Hill: New York, 1965.

9. Hwu, J. R.; Tsay, S. C.; Cheng, B. L. In The Chemistry of Organic Silicon Compounds Vol. 2, Rappoport, Z.; Apeloig, Y., Eds., Wiley: Chichester, 1998, Chapt. 8.

10. Mileshkevich, V. P.; Novikova, N. F. Usp. Khim. 1981, 50, 85.

11. Cartledge, F. K. Organometallics. 1983, 2, 425.

12. Shimizu, N.; Takesuke, N.; Yamamoto, A.; Tsutsumi, T.; Yasuhara, S.; Tsuno, Y. Chem. Lett. 1992, 1263.

13. Käppler, K.; Scheim, U.; Rühlmann, K.; Porzel, A. J. Organomet. Chem. 1992, 441, 15.

14. Käppler, K.; Scheim, U.; Rühlmann, K. Phosphorus, Sulfur and Silicon. 1995, 106, 203.

15. Charton, M. J. Am. Chem. Soc. 1975, 97, 3691.

16. DeTar, D. F. J. Org. Chem. 1980, 45, 5166.

17. Hancock, C. K.; Meyers, E. A.; Yager, B. Y. J. Am. Chem. Soc. 1961, 83, 4211.

18. Palm, V.A. Fundamentals of the Quantitative Theory of Organic Reactions (in Russian), Khimiya; Leningrad, 1967, Chapt. 10.

19. MacPhee, J.A.; Panaye, A.; Dubois, J.-E. Tetrahedron. 1978, 34, 3553.

20. Charton, M. J. Am. Chem. Soc. 1975, 97, 3694.

21. Lukevics, E.; Dzintara, M. Zh. Obshtch. Khim. 1984, 54, 1105.

22. Tan, H.; Yoshikawa, A.; Gordon, M. S.; Espenson, J. H. Organometallics. 1999, 18, 4753.

23. Kohlheim, J.; Lange, D.; Kelling, H. J. prakt. Chem. 1996, 338, 660.

24. Andrianov, K. A.; Tartakovskaya, L. M.; Kopylov, V. M.; Sementsova, Zh. N. Zh. Obshtch. Khim. 1975, 45, 112.

25. Lukevics, E.; Dzintara, M. Zh. Obshtch. Khim. 1981, 51, 2043.

26. Panov, D.; Ploom, A.; Tuulmets, A. Phosphorus, Sulfur and Silicon. Submitted

27. Käppler, K.; Porzel, A.; Scheim, U.; Rühlmann, K. J. Organomet. Chem. 1991, 402, 155.

28. Schott, G.; Ebel, P. Z. anorg. allg. Chem. 1963, 325, 169. 